\title{
DEVELOPMENT AND VERIFICATION TEST OF ELECTRICAL INDICATOR FOR 1.5 KV DC FEEDER IN ORDER TO VISUALIZE ENERGIZED CONDITION
}

\author{
YOSHIHISA MITOMA \& KEITA HASEGAWA \\ East Japan Railway Company, Japan
}

\begin{abstract}
The overhead contact line system is essential to supply traction power to trains. $1.5 \mathrm{kV}$ DC is mainly adopted in the metropolitan area. The overhead wires are congested near the traction substations and the large scale passenger stations. When on-site workers start maintenance or improvement work for the overhead contact line system, the overhead wires should be de-energized individually in order to avoid electrical shock. We have developed the electrical indicator for $1.5 \mathrm{kV}$ DC feeder in order to visualize energized or de-energized condition. The electrical indicator consists of a cylindrical electrode, detection circuits, rechargeable batteries, charging circuits, solar cells and LEDs. The electrical indicator can visualize energized or de-energized condition on the overhead wires by the LEDs. The cylindrical electrode covers the overhead wire and detects the ripple voltage. The earthing wire has been successfully removed by focusing on the electric field, although the detection of $1.5 \mathrm{kV}$ DC voltage basically needs the earthing wire to settle the reference potential. A fail-safe system which will activate the LED in event of a malfunction of the electrical indicator has been also devised, even during de-energized condition. Subsequently, the verification test in the laboratory, where an overhead wire on $1.5 \mathrm{kV}$ DC is able to be energized, have been conducted. Threshold voltage level of the LED for the energized condition has been founded by measuring the ripple voltage using the oscilloscope. Moreover, the visibility of LEDs at a distance of $5 \mathrm{~m}$ in de-energized condition have been confirmed. In conclusion, we have developed the electrical indicator for $1.5 \mathrm{kV} \mathrm{DC}$ feeder and conducted verification test, enabling visualization of energized or de-energized condition. We will continue to make further improvements on electrical indicator and aims to introduce the device into the field for practical use in the near future.

Keywords: electrical indicator, $1.5 \mathrm{kV}$ DC feeder, visualizing energized or de-energized condition.
\end{abstract}

\section{INTRODUCTION}

East Japan Railway Company manages and operates many electrical facilities such as power stations, substations, electric power transmission lines, power distribution lines and so on. The overhead contact line system is essential to supply traction power to trains. $1.5 \mathrm{kV} \mathrm{DC}$ is mainly adopted in the metropolitan area. The overhead wires are congested near the traction substations and the large scale passenger stations. When on-site workers start maintenance or improvement work for the overhead contact line system, the overhead wires should be de-energized individually in order to avoid electrical shock. Basically, on-site workers start maintenance or improvement work after checking de-energized condition and attaching the earthing wire to the overhead contact line system based on the work permit and procedure.

However, it is sometimes difficult for the congested overhead wires near the traction substation and the large scale passenger stations to be de-energized at the same time due to their operating schedule. This condition might cause the electrical shock especially when onsite workers misunderstand the de-energized area due to the complexity of the overhead wires or a safety lapse might happen during maintenance. We have developed the electrical indicator for $1.5 \mathrm{kV}$ DC feeder in order to visualize energized or de-energized condition. It would be beneficial to avoid both electrical shock and mistakenly attaching the earthing wire 
to the energized wire. General outline of East Japan Railway Company's electrical facilities is shown in Fig. 1. The image of the congested overhead wires near the traction substation is shown in Fig. 2.

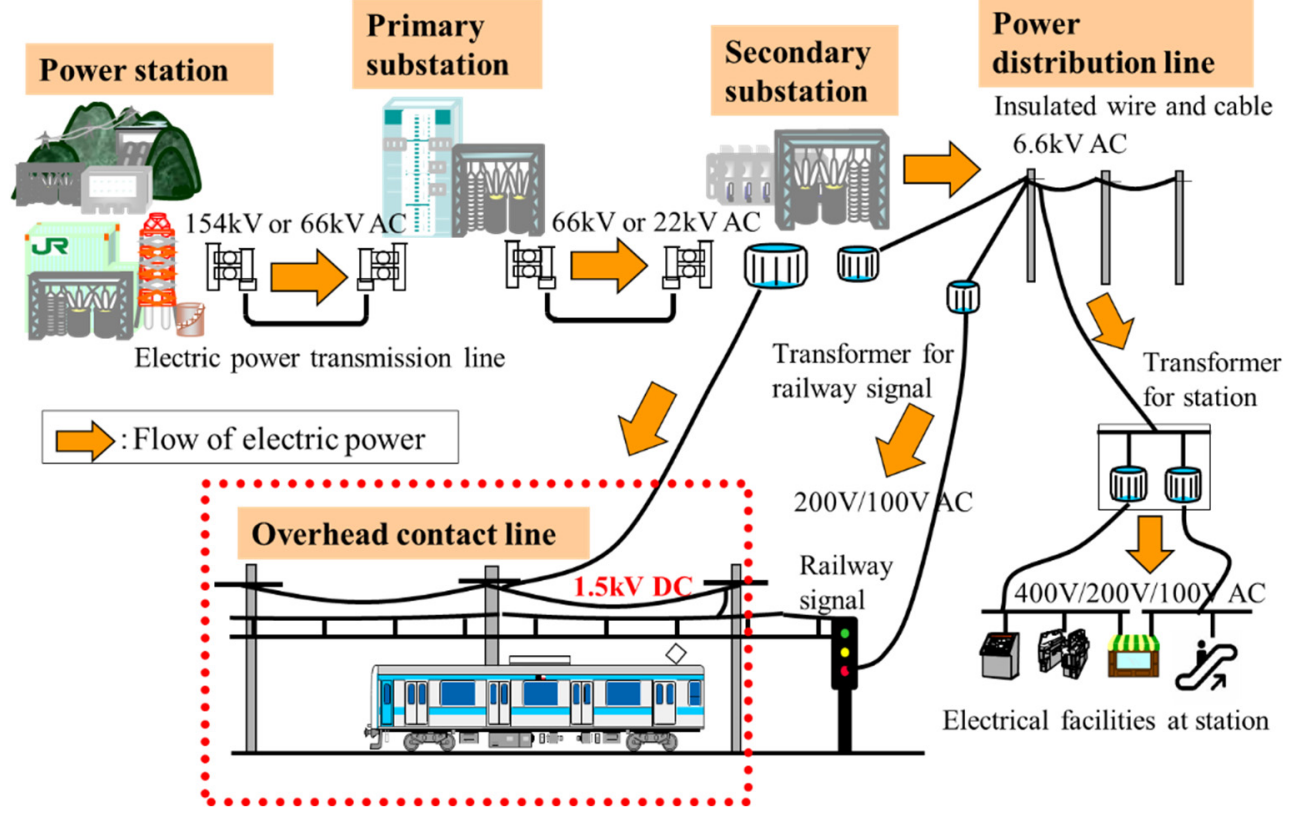

Figure 1: General outline of East Japan Railway Company's electrical facilities.

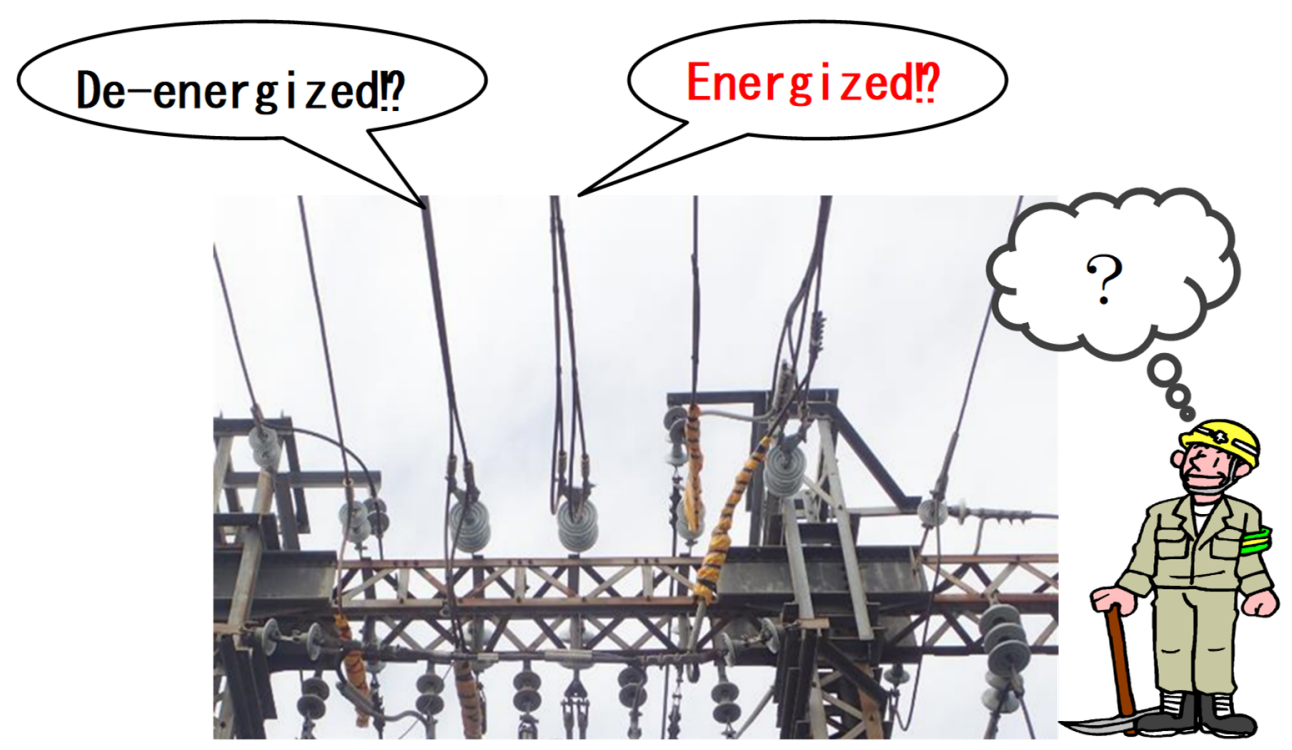

Figure 2: The image of the congested overhead wires near the traction substation. 


\section{THEORY AND FEATURE OF ELECTRICAL INDICATOR}

We focus on $1.5 \mathrm{kV}$ DC overhead contact line system. The theory and feature of electrical indicator are described as below.

\subsection{Detection method}

When the overhead wires are energized, they contain the ripple voltage. It is occurred when the rectifier converts AC voltage to DC voltage by three-phase full-wave rectification. The cylindrical electrode covers the overhead wire and detects the ripple voltage. The earthing wire has been successfully removed by focusing on the electric field, although the detection of $1.5 \mathrm{kV}$ DC voltage basically needs the earthing wire to settle the reference potential.

\subsection{Indication method}

The energized or de-energized condition on the overhead wires is able to be visualized by attaching the LEDs on the electrical indicator. When the $1.5 \mathrm{kV}$ overhead wires are energized, the electrical indicator is not activated and LEDs remains deactivated. On the other hand, when the $1.5 \mathrm{kV}$ overhead wires are de-energized, the electrical indicator is activated and LEDs remains activated. A fail-safe system which will activate the LED in event of a malfunction of the electrical indicator has been also devised, even during de-energized condition. Small rechargeable batteries have been installed inside the electrical indicator and solar cells on it because the power source of lighting LEDs is lost and LEDs cannot be activated in the event of de-energized condition.

\subsection{Attachment method}

Basically, on-site workers start maintenance or improvement work after checking deenergized condition and attaching the earthing wire to the overhead contact line system based on the work permit and procedure. We decided to attach the electrical indicator directly to the overhead wire for the purpose of the subsidiary measures of checking de-energized condition and attaching the earthing wire to the overhead contact line system. The target overhead wire would be around $6.5 \mathrm{~m}$ from the ground. Taking into consideration the average human eye height of $1.5 \mathrm{~m}$, LEDs which have a visibility range of $5 \mathrm{~m}$ have been selected.

\section{CONFIGURATION OF ELECTRICAL INDICATOR}

The electrical indicator consists of a cylindrical electrode, detection circuits, rechargeable batteries, charging circuits, solar cells and LEDs. The electrical indicator can visualize energized or de-energized condition on the overhead wires by the LEDs. The cylindrical electrode covers the overhead wire and detects the ripple voltage. Outline of DC electrical indicator is shown in Fig. 3. Images of the cylindrical electrode are shown in Fig. 4.

\section{OUTLINE OF VERIFICATION TESTS}

The verification test in the laboratory, where an overhead wire on $1.5 \mathrm{kV} \mathrm{DC}$ is able to be energized, have been conducted. The applied voltage to the overhead wire was measured by the voltage recorder, and the ripple voltage, which was incorporated in the electrical indicator, was measured by the oscilloscope. Threshold voltage level of the LED for the energized condition has been founded by measuring the ripple voltage using the oscilloscope. Moreover, the visibility of LEDs at a distance of $5 \mathrm{~m}$ in de-energized condition have been confirmed. Experimental circuit composition is shown in Fig. 5. Image of experimental circuit composition is shown in Fig. 6. 


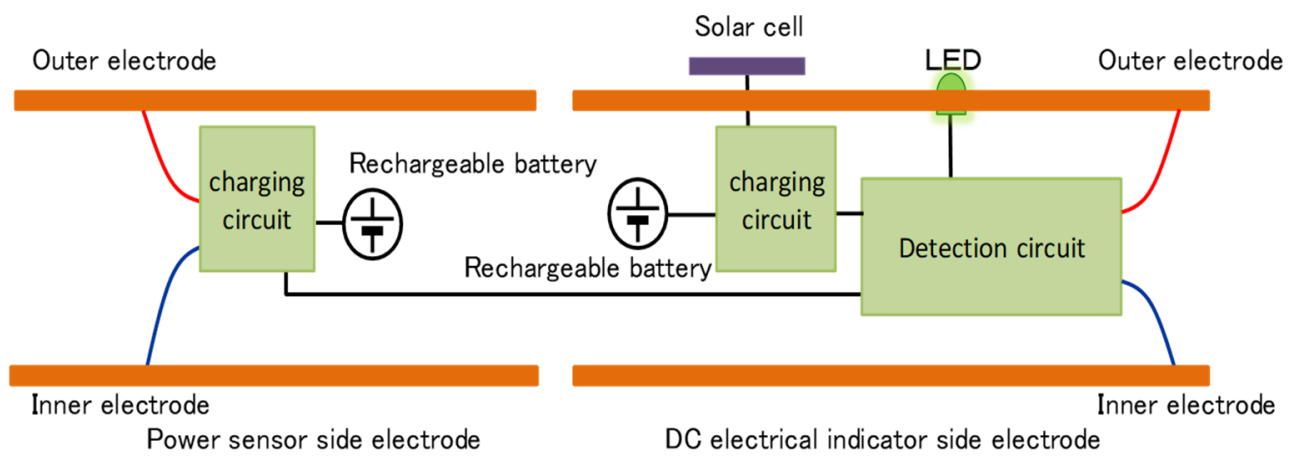

Figure 3: Outline of DC electrical indicator.

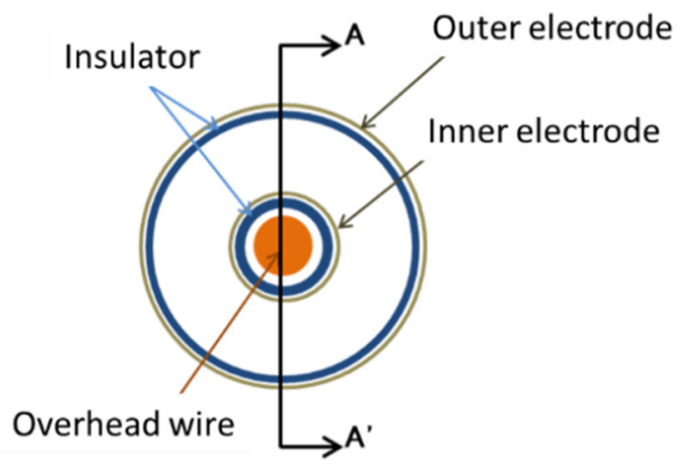

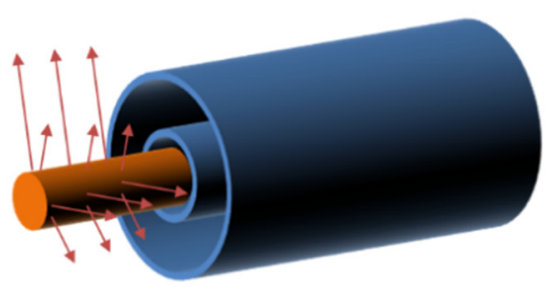

Detecting the ripple voltage

Figure 4: Images of the cylindrical electrode.

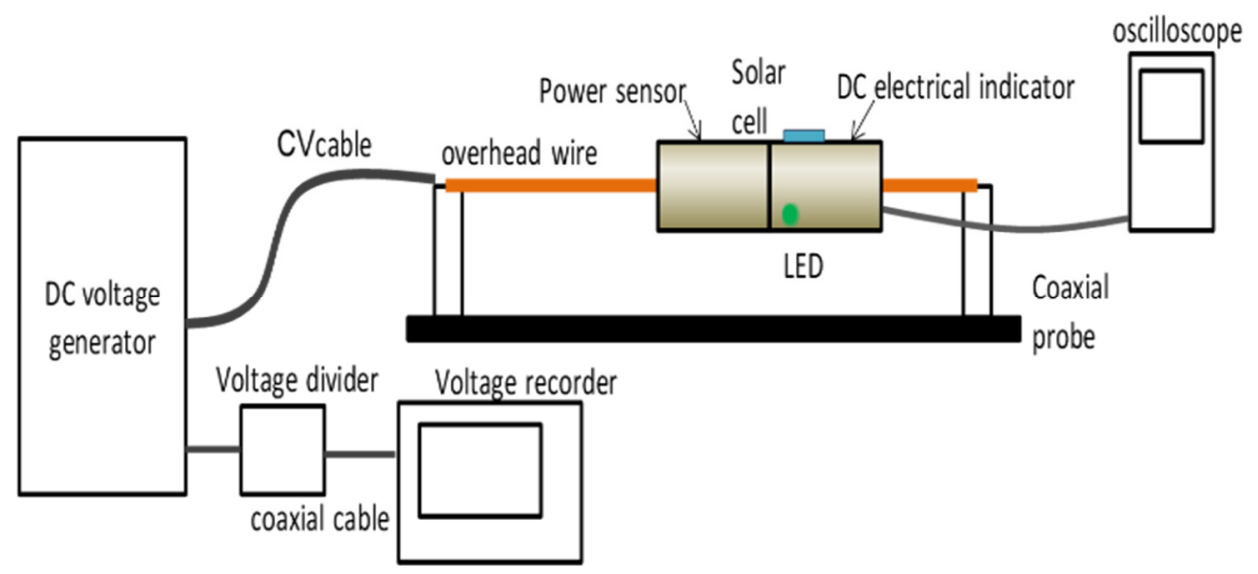

Figure 5: Experimental circuit composition. 


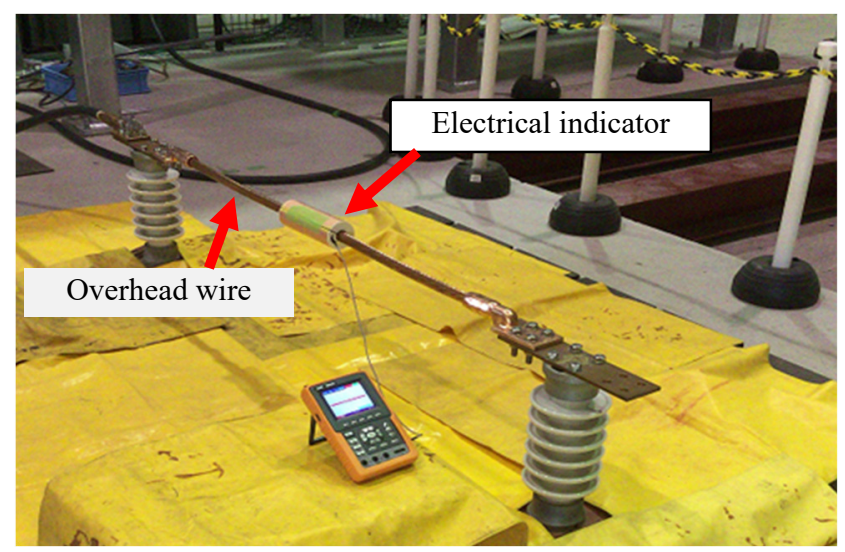

Figure 6: Image of experimental circuit composition.

\section{RESULT OF VERIFICATION TESTS}

The detection voltage level of the voltage detector which on-site workers usually use at site is more than $750 \mathrm{~V} \mathrm{DC}$ referring to the voltage detector. We tried to calculate the threshold voltage level by measuring the applied voltage and the ripple voltage based on the several transformer setting voltage. Then, we have calculated the approximate equation as

$$
\mathrm{y}=0.0111 \mathrm{x}+24.375
$$

where $\mathrm{x}=$ the applied voltage $(\mathrm{V}) ; \mathrm{y}=$ the ripple voltage $(\mathrm{V})$.

When the overhead wire is applied in $750 \mathrm{~V} \mathrm{DC}$, the ripple voltage is $32.7 \mathrm{Vp}-\mathrm{p}$ and the threshold voltage level of the detection circuit of the electrical indicator is $620 \mathrm{mV}$. Therefore, we have decided the threshold voltage level of LEDs for the energized condition as $620 \mathrm{mV}$. Relation between applied voltage and ripple voltage is shown in Table 1 and Fig. 7.

We have selected the LEDs colour as green, which is adopted in the signal of the public transportation as safe. And green also has good visibility. The visibility of LEDs at a distance of $5 \mathrm{~m}$ in de-energized condition have been confirmed through the experiment. Images of LEDs of the electrical indicator are shown in Fig. 8.

Table 1: Relation between applied voltage and ripple voltage.

\begin{tabular}{|c|c|c|c|c|c|}
\hline $\begin{array}{r}\text { Transformer } \\
\text { setting voltage } \\
{[\mathrm{V}]} \\
\end{array}$ & $\begin{array}{r}\text { (Voltage recorder) } \\
\text { DC voltage } \\
{[\mathrm{V}]}\end{array}$ & $\begin{array}{r}\text { (Voltage recorder) } \\
\text { Ripple voltage } \\
{\left[V_{p}-p\right]} \\
\end{array}$ & \begin{tabular}{|c} 
Ripple to DC \\
voltage \\
Voltage Proportion[\%]
\end{tabular} & $\begin{array}{r}\text { (Oscilloscope) } \\
\text { Detection voltage } \\
{[\mathrm{mV}]} \\
\end{array}$ & $\begin{array}{l}\text { Detection for } \\
\text { ripple voltage } \\
\text { Voltage ratio } \\
\end{array}$ \\
\hline 1788 & 2130 & 48 & 2.25 & 880 & 0.018 \\
\hline 1491 & 1750 & 44 & 2.51 & 820 & 0.019 \\
\hline 1192 & 1400 & 40 & 2.86 & 780 & 0.020 \\
\hline 893 & 1050 & 36 & 3.43 & 680 & 0.019 \\
\hline & & & & Average value & 0.019 \\
\hline
\end{tabular}




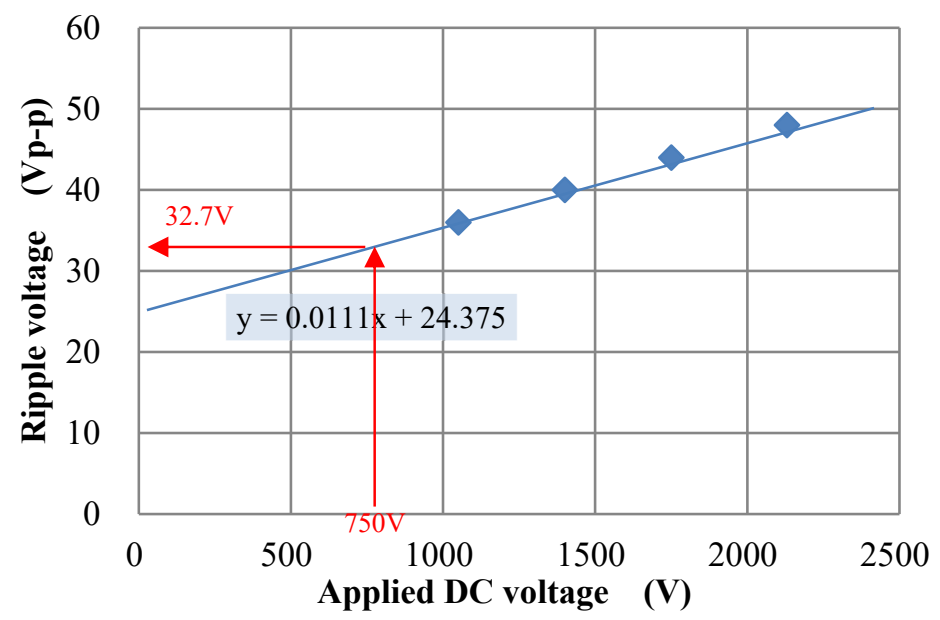

Figure 7: Relation between applied voltage and ripple voltage.

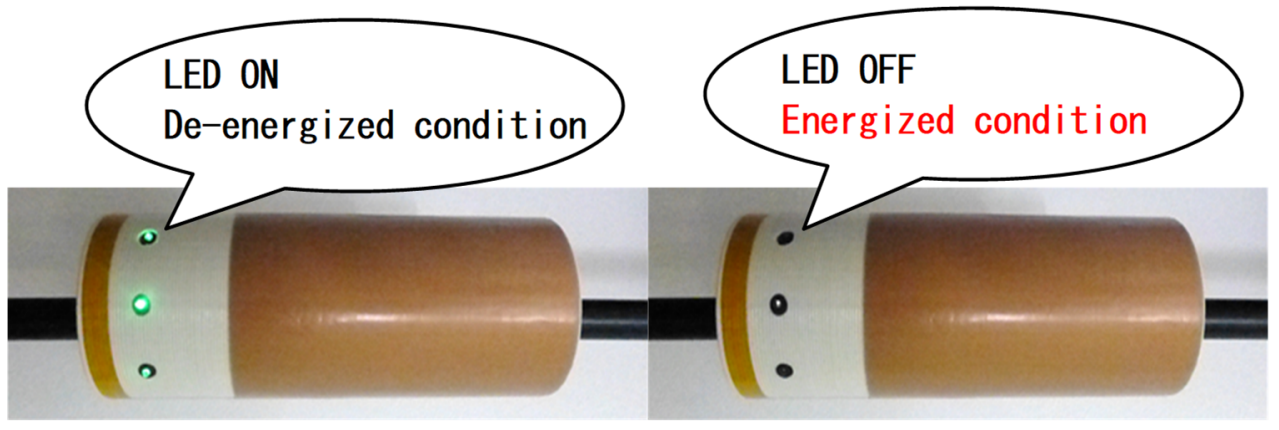

Figure 8: Images of LEDs of the electrical indicator.

\section{CONCLUSION}

We have developed the electrical indicator for $1.5 \mathrm{kV}$ DC feeder and conducted verification test, enabling to visualize energized or de-energized condition. Threshold voltage level of the LED for the energized condition has been founded by measuring the ripple voltage using the oscilloscope. Moreover, the visibility of LEDs at a distance of $5 \mathrm{~m}$ in de-energized condition have been confirmed. We will continue to make further improvements on electrical indicator and aims to introduce the device into the field for practical use in the near future.

\section{ACKNOWLEDGEMENTS}

We would like to thank Masahiro Tsuchiya of National Institute of Information and Communications Technology, Kazuhisa Iwata of A.C.S. Inc. and Michiaki Kouda of East Japan Railway Company for supporting development and verification test of electrical indicator for $1.5 \mathrm{kV}$ DC feeder. 


\section{REFERENCES}

[1] Tsuchiya, M., Shiozawa, T. \& Harakawa, S., Electric field sensing and imaging by noninvasive parallel-plate sensor. IEICE Electronics Express, 11(18), pp. 1-7, 2014.

[2] Hasegawa, K., Mitoma, Y. \& Kouda, M., Basic verification of DC electrical indicator. IEE Japan, pp. 383-384, 2019. 